\title{
Avaliação sérica de danos musculares e oxidativos em atletas após partida de futsal
}

\author{
Serum measurement of muscle and oxidative damage in soccer \\ players after a game
}

\author{
Cláudio Teodoro de Souza 1,2,3 \\ Cleber de Medeiros 1,2,3 \\ Luciano Acordi da Silva 2,3 \\ Tiago Cesar Silveira \\ Paulo Cesar Silveira 2,3 \\ Cleber Aurino de Pinho 1,3 \\ Débora da Luz Scheffer 1,3 \\ Ricardo Aurino Pinho 1,2,3
}

1 Universidade do Extremo Sul Catarinense. Curso de Educação Física. Criciúma, SC. Brasil

2 Programa de PósGraduação em Ciências da Saúde

3 Laboratório de Fisiologia e Bioquímica do Exercício

Recebido em 05/09/08 Revisado em: 23/10/09 Aprovado em 27/11/09
Resumo - O futsal é uma modalidade esportiva que requer súbita aceleração e desaceleração com brusca mudança de direção. Este esporte expõe seus praticantes a grandes impactos, causando danos musculares e oxidativos. O objetivo desta pesquisa foi avaliar os níveis séricos de marcadores de danos musculares e oxidativos em atletas após jogo de futsal. Participaram do estudo, seis atletas de futsal, com idade média (21,2 $\pm 0,98$ anos), peso $(67,1 \pm 5,5 \mathrm{~kg})$ e altura $(171,0 \pm 0,07 \mathrm{~cm})$. As coletas foram obtidas 30 minutos antes do jogo 1 (Pré-jogo); imediatamente após o jogo 1 (pós-jogo 1) e imediatamente após o segundo jogo (pós-jogo 2), que foi realizado 24 horas após o jogo 1. O soro foi utilizado para avaliações séricas de creatina quinase, dano protéico e lipídico. As concentrações de creatina quinase, peroxidação lipídica (xilenol) e carbonilação de proteína (carbonil) foram significativamente maiores após o término dos jogos 1 e 2, quando comparadas aos valores pré jogo. Os valores de sulfidrila foram menores após o término dos jogos 1 e 2, quando comparados aos valores pré jogo. Nenhuma diferença foi observada quando comparados os valores após jogo 1 e o jogo 2 em todos os parâmetros analisados. Coletivamente, os resultados demonstram que a partida de futsal provoca danos musculares e oxidativos. Surpreendentemente, não houve incremento nos parâmetros avaliados ao final do jogo 2. Devido ao reduzido conhecimento em relação ao tempo de recuperação após uma partida de futsal, acredita-se que este estudo seja de grande importância para os profissionais que trabalham com esse esporte.

Palavras-chave: Futsal; Esporte; Dano muscular; Estresse oxidativo.

Abstract - Futsal is a sport that requires sudden acceleration and deceleration with abrupt changes in direction. The marked impacts experienced by futsal players lead to muscle and oxidative damage. The objective of this study was to evaluate the serum levels of markers of muscle and oxidative damage in futsal players after a game. Six players with a mean age of 21.2 \pm 0.98 years, weight of $67.1 \pm 5.5 \mathrm{~kg}$ and height of $171.0 \pm 0.07 \mathrm{~cm}$ participated in this study. Measurements were obtained 30 minutes before game 1 (pre-game), immediately after game 1 (post-game 1), and immediately after a second game (post-game 2), which was performed 24 hours after game 1. Serum was collected for the evaluation of creatine kinase and of damage to proteins and lipids. Creatine kinase concentrations, lipid peroxidation (xylenol) and protein carbonylation were significantly higher after games 1 and 2 when compared to pre-game values. Sulfhydryl levels were lower after the end of games 1 and 2 compared to pre-game values. No difference in any of the parameters analyzed was observed between post-game 1 and post-game 2. Taken together, the results demonstrate that a futsal match provokes muscle and oxidative damage. Surprisingly, no increase in the parameters studied was observed after game 2. In view of the limited knowledge about the time of recovery after a futsal match, this study may provide important information to professionals working with this sport.

Key words: Futsal; Sport; Muscle damage; Oxidative stress. 


\section{INTRODUÇÃO}

O futsal é um esporte que vem se popularizando nos últimos tempos. Como no futebol de campo, o futsal também se modificou nos últimos anos, exigindo muito da capacidade física do atleta. Com esta evolução, o futsal se tornou um esporte de alto impacto e alta intensidade ${ }^{1}$. Por ser uma modalidade esportiva na qual a movimentação em quadra requer súbita aceleração e desaceleração com brusca mudança de direção, o futsal expõe as estruturas osteomusculares de seus praticantes a grandes impactos, aumentando o risco de lesão ${ }^{2}$. Com o avanço da ciência do esporte, tem-se utilizado avaliações específicas para melhorar o desempenho dos atletas. Dentre eles, a creatina quinase (CK) é frequentemente utilizada como marcador de dano ao tecido muscular, sobretudo após o exercício de força ou outros exercícios que exijam ações predominantemente excêntricas ${ }^{3-5}$. As fibras musculares, usualmente, sofrem processos de regeneração. Novas fibras musculares regeneram dentro da estrutura do tecido conectivo no músculo danificado.

Em 2001, Li et al. ${ }^{6}$ demonstraram que os níveis de CK apresentam-se aumentados após o exercício excêntrico, com ênfase após 72 horas. Possivelmente, os mecanismos iniciais da lesão que ocorre no músculo, apresentado por níveis aumentados de CK, estão diretamente ligados à geração de radicais livres. Em adição, aumento no consumo do oxigênio durante o exercício promove acréscimo na produção de espécies reativas de oxigênio $(\mathrm{ERO})^{7-8}$, fator que pode contribuir para as lesões musculares e processos inflamatórios9. Entretanto, o treinamento físico altera o balanço e pode restabelecer o equilíbrio entre os agentes pró e antioxidantes, porém esses efeitos são dependentes da frequência, intensidade e duração do treinamento ${ }^{10}$.

$\mathrm{O}$ aumento das espécies reativas de oxigênio induzido pelo exercício físico parece representar um desafio para o sistema antioxidante. Em 1992, Ji e $\mathrm{Fu}^{11}$ comprovaram que em músculo esquelético a resposta aguda ao exercício físico produzia um aumento da peroxidação lipídica, estimulando a atividade do sistema antioxidante como a glutationa-peroxidase, superóxido dismutase e catalase; demonstrando que os aumentos nas atividades dessas enzimas sugeriam um concomitante aumento nas espécies reativas de oxigênio. Recentemente, Niess e Simon ${ }^{12}$ demonstraram que a adaptação dos sistemas antioxidantes endógenos pode refletir um importante potencial mecanismo de defesa, responsável pela tolerância aumentada ao exercício do músculo esquelético quando realizado cronicamente.

Sendo assim, o objetivo deste estudo foi avaliar os níveis séricos de marcadores de danos musculares e marcadores de dano oxidativo em atletas após jogo de futebol de salão. Devido ao restrito conhecimento em relação ao tempo de recuperação após uma partida de futsal, acredita-se que este estudo seja de grande importância para os profissionais que trabalham com esse esporte.

\section{PROCEDIMENTOS METODOLÓGICOS}

O projeto deste trabalho foi aprovado pelo Comitê de Ética da Universidade do Extremo Sul Catarinense (protocolo n. 272/2008). Participaram do presente estudo seis atletas praticantes de futsal, com média de idade de (21,2 $\pm 0,98$ anos), peso $(67,1 \pm 5,51 \mathrm{Kg})$ e altura $(171,0 \pm 17 \mathrm{~cm})$.

Protocolo das coletas de sangue e preparo das amostras.

A coleta do sangue foi realizada sob responsabilidade de uma enfermeira credenciada, seguindo todos os cuidados de higiene e assepsia. Foram coletados $10 \mathrm{~mL}$ de sangue, 30 minutos antes do jogo 1 (Préjogo); imediatamente após o jogo 1 (pós-jogo 1) e imediatamente após o segundo jogo (pós-jogo 2), que foi realizado 24 horas após o jogo 1 . Após as coletas, o sangue foi centrifugado a $5.000 \mathrm{rpm}$ para posteriores análises bioquímicas.

\section{Ensaio Bioquímico}

Marcador de dano muscular. A creatina quinase foi determinada com auxílio de kit específico fornecido pela Labtest Diagnóstica SA. A dosagem foi realizada a partir de sistema enzimático com reação de ponto final em amostras de soro dos atletas, segundo as orientações técnicas do fabricante.

Xilenol laranja. Foi determinado em soro como marcador de peroxidação lípidica. Este método quantifica a formação de hidroperóxidos, que é um produto da lipoperoxidação. Baseia-se no principio de que hidroperóxidos oxidam ferro a íon férrico e por sua vez este íon se liga ao corante xilenol laranja ${ }^{13}$.

Carbonilação de Proteínas (CP). Os danos oxidativos em proteínas foram determinados em soro através da determinação de grupo carbonil baseados na reação com dinitrofenilhidrazina ${ }^{14}$. O conteúdo de carbonil foi determinado espectrofotometrica- 
mente em $370 \mathrm{~nm}$, usando um coeficiente 22.0000 Molar ${ }^{1}$.

Conteúdo Total de Tióis (TT). Foi determinado em soro numa reação dos grupos tióis com 5,5' ditióbis (2 acido nitro-benzóico) (DTNB), gerando um derivado de coloração amarela e lido espectrofotometricamente a $412 \mathrm{~nm}^{15}$. Essa técnica tem por objetivo avaliar o grupo SH (sulfidrila) não oxidados.

Determinação da Proteína. A quantidade de proteínas nos ensaios do xilenol, carbonil e sulfidrila foram mensuradas usando a técnica de LOWRY' ${ }^{16}$.

\section{Análise Estatística}

Os dados foram expressos como média e erro padrão da média. As diferenças entre pré-jogo, pós-jogo 1 e pós-jogo 2 foram avaliadas utilizando análise de variância (ANOVA) para medidas repetidas. Todos os pressupostos de testes paramétricos foram atendidos; os dados apresentaram distribuição normal. Foi utilizado o SPSS (Statistical Package for the Social Sciences) versão 12.0 como pacote estatístico e quando encontrado diferença significante, foi realizado teste de post-hoc Test Tukey, foi considerado o $\mathrm{p}<0,05$ como significante.

\section{RESULTADOS}

Creatina Quinase - A creatina quinase tem sido usada amplamente na literatura como marcador de lesão muscular; dessa forma, o presente estudo avaliou os níveis de CK no soro dos atletas. Estes achados demonstram um aumento significativo nos níveis de CK imediatamente após o término dos jogos 1 e $2(372,6 \pm 53,4$ e 408,8 4 68,8 U/L, respectivamente), quando comparados aos valores pré jogo (256,1 $\pm 23,6 \mathrm{U} / \mathrm{L}$ ), (jogo 1 versus pré jogo; $\mathrm{p}=0,048$ e jogo 2 versus pré jogo, $\mathrm{p}=0,021$ ) (Figura 1A). Isso corresponde a um aumento de $32,2 \%$ e $38,3 \%$ (pré-jogo e jogo 1 e 2, respectivamente). Nenhuma diferença significativa foi observada quando comparados os valores de CK entre jogo 1 e o jogo 2 (Figura 1A).

Marcador de danos em lipídeos - As espécies reativas de oxigênio podem atacar as moléculas lipídicas para se estabilizarem, isso pode resultar em danos nas estruturas celulares resultando num processo chamado de peroxidação lipidica. Para avaliar se uma partida de futsal aumenta os danos em estruturas lipídicas induzido por radicais livres, utilizou-se a técnica do xilenol laranja. Estes resultados demonstraram aumento de $37 \%$ e $42 \%$ imediatamente após o primeiro e segundo jogo, respectivamente, quando comparados à condição pré-jogo (Figura 1B). Quando comparado os níveis de lipoperoxidação entre atletas do jogo 1 e 2, foi verificado um aumento de $5 \%$ o que não mostrou ser significativo (Figura 1B).
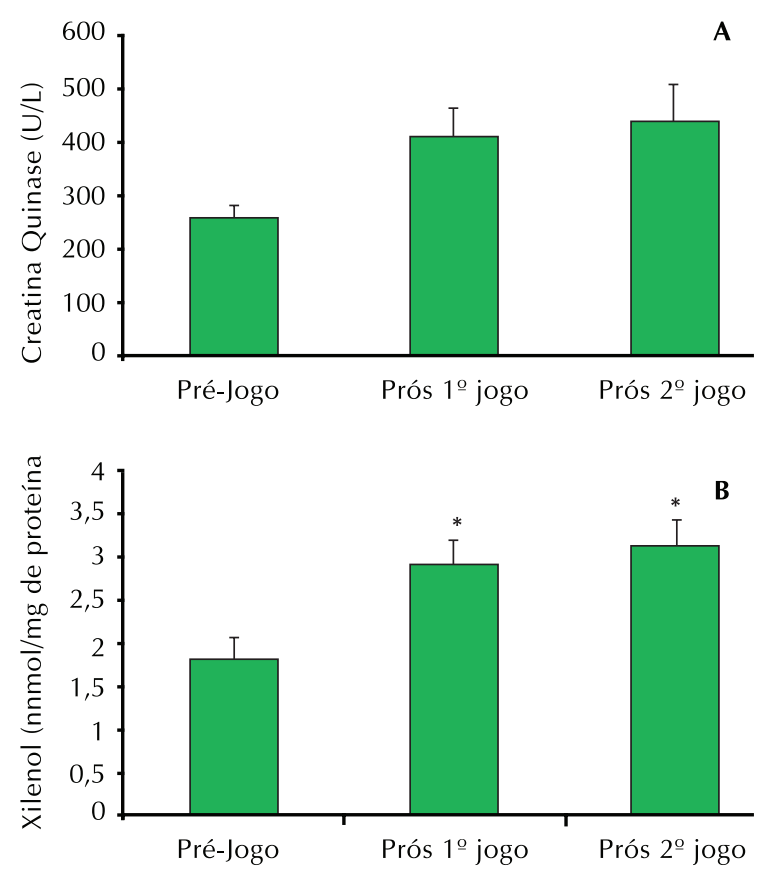

Figura 1. Avaliação de dano muscular e lipoperoxidação.

A partir de amostras de soro de jogadores de futsal em condições pré-jogo, imediatamente após jogo 1 e jogo 2; podem-se analisar os níveis de CK (A) e de lipoperoxidação (B) conforme materiais e métodos. Os valores são apresentados como Média $\pm E P M$, os resultados de CK foram expressos em U/L e Xilenol nmol/mg de proteína. ${ }^{*} \mathrm{p}<0,05$ versus a condição pré-jogo.

Avaliação de dano em proteínas - A produção excessiva das EROs pode resultar fisiologicamente em danos protéicos. Foram utilizadas duas técnicas para quantificar as lesões em proteínas, a carbonilação de proteína $(\mathrm{CP})$ e o conteúdo de tióis totais (TT) não oxidado. Os resultados mostraram aumento de $132 \%$ nos níveis de CP em soro de atletas de futsal, após jogo $1(2,2 \pm 0,90$ versus 5,1 \pm 0,72 $\mathrm{nmol} / \mathrm{mg}$ de proteína, pré-jogo e pós jogo 1 , respectivamente; $p=0,0001)$ e após jogo $2(2,2 \pm 0,90$ versus $6,5 \pm 1,8 \mathrm{nmol} / \mathrm{mg}$ de proteína, $\mathrm{p}=0,0012$ ) (Figura 2A). Nenhuma diferença significativa foi observada entre os níveis de carbonilação entre jogo 1 e jogo 2 (Figura 2A). Quanto aos tióis totais, observa-se redução de $41 \%$ e 32\% imediatamente 
após o primeiro e segundo jogo, respectivamente, comparado à condição pré-jogo (Figura 2B). Não houve diferença na tiolação de proteínas entre atletas do jogo 1 e 2 (Figura 2B).
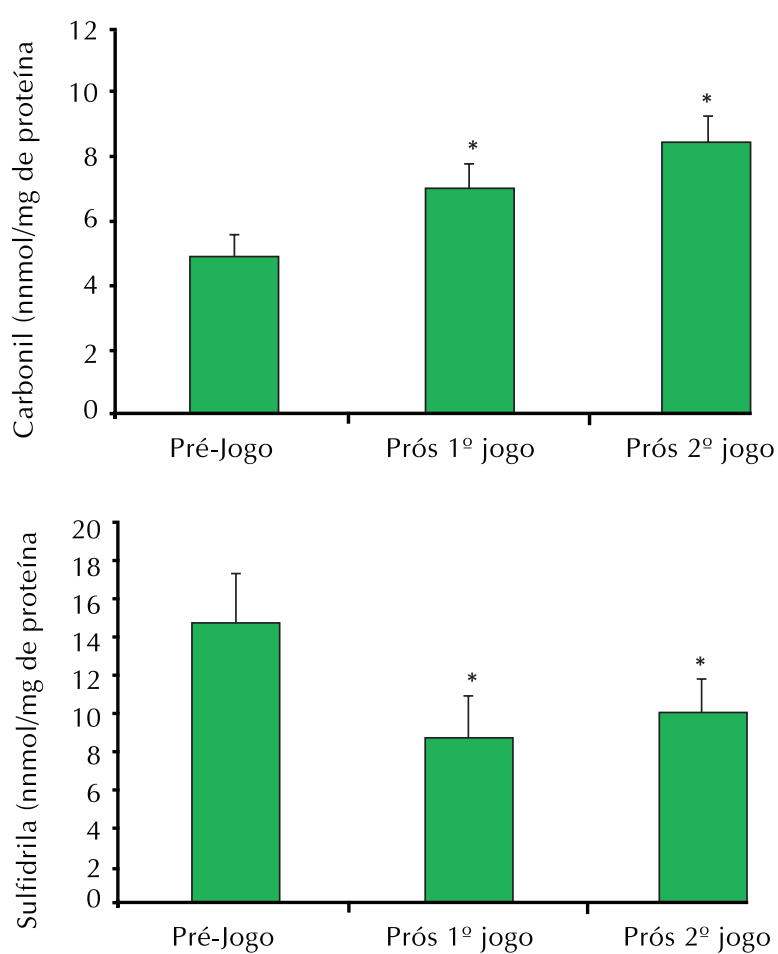

Figura 2. Quantificação de dano em proteínas.

Condições pré-jogo (pré-jogo), imediatamente após o jogo 1 (pós jogo 1) e após o jogo 2 (pós jogo 2), amostras de sangue dos atletas foram coletadas para a analise do dano em proteínas. A carbonilação de proteína (A) e o conteúdo de Tióis Totais (B) foram determinados de acordo com materiais e métodos. Os valores são apresentados em Média \pm EPM e expressos em (nmol/mg proteína). * p<0,05 versus a condição pré-jogo.

\section{DISCUSSÃO}

Semelhante ao futebol, os atletas de futsal realizam uma sucessão de esforços intensos e breves em ritmos diferentes, com um nível de exigência funcional muscular muito alto, como nas corridas, nos saltos, nas movimentações táticas e na técnica de condução de bola, solicitando desses atletas a mobilização máxima de suas capacidades funcionais. Estudos demonstram o alto nível de dano muscular a partir do treinamento excêntrico, com ênfase após o exercício ${ }^{2,6}$. Observa-se, também que os valores médios da concentração plasmática da CK encontrados nos jogadores de futebol sempre estiveram bem acima da média dos valores de re- ferência para sujeitos não atletas ${ }^{17}$. Porém e apesar de alguns estudos enfocarem o nível de lesão após exercício, sua relação com partidas de Futsal como também associação com o correto tempo de recuperação entre partidas, são desconhecidos.

Farthing e colabordores ${ }^{18}$ demonstraram que o exercício de alta intensidade, especialmente as atividades que envolvem contração excêntrica, são os mais eficazes para ganhar força e hipertrofia muscular, porém, são frequentemente associadas à lesão muscular. Alguns autores ${ }^{19,20}$ postulam um maior pico destes níveis de dano muscular após 48 horas à execução do exercício, caracterizado pelo aumento significativo dos níveis de CK. Em um estudo de comparação entre exercício de força com ações concêntricas e excêntricas também foram capazes de induzir dano muscular, sendo encontrado um aumento após 72 horas a partir do exercício excêntrico ${ }^{21}$. Malm et al. ${ }^{22}$, utilizando a mesma carga de trabalho, mostraram que as ações excêntricas, quando comparadas às concêntricas recrutam menor quantidade de unidades motoras, o que induz a um estresse mecânico aumentado nas fibras musculares, acarretando maior tensão por área de secção transversa ativa. As ações musculares (excêntrica, concêntrica e isométrica) associadas ao treinamento de força causam dano muscular, entretanto, outros pesquisadores reconhecem que a ação excêntrica causa maior magnitude de dano muscular ${ }^{23}$.

Uma partida de futsal promove um incremento do consumo de oxigênio, fator que propicia um aumento da formação de radicais livres. Ascensão et al. ${ }^{24}$ analisaram o impacto bioquímico após um jogo de futebol. Neste estudo, foi demonstrada uma redução significativa na sulfidrila no período de 30 minutos, 24 e 48 horas pós exercício, e um aumento de antioxidantes no período de $30 \mathrm{minu}$ tos, 24 e 48 horas pós-exercício ${ }^{24}$. Como se sabe, à redução nos níveis de sulfidrila indica maior dano oxidativo à proteína. Isso se deve ao fato de que RL atacam os aminoácidos das proteínas oxidando os grupamentos sufidrila. Os dados mostraram que um jogo de futebol aumenta os níveis de estresse oxidativo e lesão muscular durante todo o período de recuperação de 72 horas $^{24}$. Resultados semelhantes foram observados no presente estudo. Entretanto, o aumento das enzimas antioxidantes pós-exercício pode ser considerado como um mecanismo defensivo da célula sob estresse oxidativo. Em 1995, Clarkson $^{25}$ demonstrou que o treinamento físico promove um aumento do sistema antioxidante e redução da peroxidação lipídica. A formação pode ter efeitos positivos e negativos sobre o estresse 
oxidativo, dependendo de variáveis como: tipo, intensidade e volume. Além disso, este mecanismo parece estar envolvido na fadiga muscular e pode levar ao overtraining ${ }^{14}$.

Após um jogo de futebol, ocorre um aumento na produção de ERO, que pode levar à oxidação de diversos aminoácidos, formando, então, grupos carbonilas. A carbonilação de proteína tem sido usada como um bom marcador de estresse oxidativo ${ }^{26}$. Os resultados do presente estudo demonstram um incremento na carbonilação de proteína após ambos os jogos (Figura 2A). Interessantemente, estes valores não foram maiores no segundo jogo. Brites et al. ${ }^{27}$ demonstraram que jogadores de futebol que participam do treinamento regular têm altos níveis de estresse oxidativo. Tauler et al. $^{28}$ reduziram o dano oxidativo em jogadores após uma partida, com a suplementação de antioxidantes mais a coenzima Q10. Talvez a utilização de antioxidantes nestes atletas possa ser uma ferramenta interessante para diminuir o dano oxidativo.

O dano muscular potencializado pelo exercício físico aumenta os níveis de radicais livres e a oxidação de lipídios e proteínas ${ }^{29}$. Alessio et al. ${ }^{30}$ analisaram dois tipos de protocolo de exercício sobre o estresse oxidativo. Tanto no exercício aeróbio exaustivo quanto no anaeróbio excêntrico foi observado aumento no dano de proteínas (carbonil), lipídios, hidroperóxidos e antioxidante total.

Sugere-se futuras pesquisas com realização das dosagens bioquímicas do sistema enzimático de defesa antioxidante dos atletas, marcadores pró-inflamatórios, marcadores de lesão muscular e o controle do estado nutricional dos jogadores, uma vez que isso possa influenciar na recuperação e no desempenho dos atletas. É possível ainda, utilizar a suplementação com antioxidante e o tratamento com crioterapia como estratégias para diminuir o estresse oxidativo e acelerar a recuperação dos jogadores.

\section{CONCLUSÃO}

Conclui-se que um jogo de futsal leva a maiores danos musculares e aumento na oxidação de lipídeos e proteínas. Mostrando que uma partida desse esporte favorece estresse oxidativo. No entanto, pelo menos com base nos parâmetros bioquímicos avaliados, e em indivíduos previamente treinados, pode-se observar que uma segunda partida, realizada 24 horas após o primeiro jogo, não demonstra incrementar nem danos musculares nem estresse oxidativo. Finalmente, em se tratando de dano muscular e estresse oxidativo, 24 horas pós-jogo parece ser recuperação suficiente para os atletas de Futsal.

\section{REFERÊNCIAS BIBLIOGRÁFICAS}

1. Gomes AC, Silva SG. Preparação física no futebol: características da carga de treinamento. In: Silva, F M, organizador. Treinamento desportivo: aplicações e implicações. João Pessoa: Editora Universitária; 2002. p. 27-35.

2. Moreira D; Godoy JRP, Braz RG, Machado GFB, Santos HFS. Abordagem cinesiológica do chute no futsal e suas implicações clínicas. Rev Bras Cinesiologia Mov 2004;12(2):81-85.

3. Motta V. Bioquímica Clínica: Princípios e Interpretações. Editora: Médica Massau; 2000.

4. Foschini D, Prestes J, Charro AM. Relação entre exercício físico, dano muscular e dor muscular de início tardio. Rev Bras de Cineantropom Desempenho Hum 2007,9(1):101-106.

5. Mougios V. Reference intervals for serum creatine kinase in athletes. Br J Sports Med 2007; 41(10):674-8.

6. Li G, Feng X, Wang S. Effects of $\mathrm{Cu} / \mathrm{Zn}$ superoxide dismutase on strain injury-induced oxidative damage to skeletal muscle in rats. Physiol Res 2005;54(2):193-9.

7. Jenkins RR, Goldfarb A. Introduction: oxidant stress, aging, and exercise. Med Sci Sports Exerc 1993;25(2):210-2.

8. Ji LL. Antioxidants and oxidative stress in exercise. Proc Soc Exp Biol Med 1999;222(3):283-92.

9. Cruzat VF, Rogero MM, Borges MC, Tirapegui J. Aspectos atuais sobre estresse oxidativo, exercícios físicos e suplementação. Rev Bras Med Esporte 2007;13 (5):336-342.

10. Pinho RA, Andrades ME, Oliveira MR, Pirola AC, Zago MS, Silveira PC, et al. Imbalance in SOD/CAT activities in rat skeletal muscles submitted to treadmill training exercise. Cell Biol Int 2006;30(10):848-53.

11. Ji LL, Fu R.Responses of glutathione system and antioxidant enzymes to exhaustive exercise and hydroperoxide. J Appl Physiol 1992;72(2):549-54.

12. Niess AM, Simon P. Response and adaptation of skeletal muscle to exercise--the role of reactive oxygen species. Front Biosci 2007;12:4826-38.

13. Jiang Y; Woollard ACS; Wolff SP. Lipid hydroperoxide measurement by oxidation of $\mathrm{Fe}+2$ in the presence of xilenol orange. Comparison with the TBA assay and an lodometric method. Lipids 1991;26:853-856.

14. Levine RL, Garland D, Oliver CN, Amici A, Climent I, Lenz AG, et al. Determination of carbonyl content in oxidatively modified proteins. Meth Enzymol 1990;186:464-478.

15. Aksenov MY and Markesberya WR. Changes in thiol content and expression of glutathione redox system genes in the hippocampus and cerebellum in Alzheimer's disease. Neurosci Lett. 2001;302:141-145.

16. Lowry OH, Rosebough NG, Faar AL, Randall RJ. Protein measurement with the folin phenol reagent. J Biol Chem 1951;193:265-275.

17. Zoppi, CC. Adaptações induzidas pelo treinamento físico no metabolismo oxidativo e sistema de defesa 
antioxidante do músculo e sangue de ratos e sua correlação com os níveis de lesão muscular. [Dissetação de Mestrado - Programa de Pós-Graduação em Bioquímica]. Campinas (SP): Universidade Estadual de Campinas; 1999.

18. Farthing JPE, Chilibeck PD. The effects of eccentric and concentric training at different velocities on muscle hypertrophy. Eur J Appl Physiol 2003;89:578-586.

19. Milias GA, Nomikos T, Fragopoulou E, Athanasopoulos S, Antonopoulou S. Effects of baseline serum levels of Se on markers of eccentric exercise-induced muscle injury. Biofactors 2006;26(3):161-170.

20. Pantoja PD, Alberton CL, Pilla C, Vendrusculo AP, Kruel LF. Effect of resistive exercise on muscle damage in water and on land. J Strength Cond Res 2009;23(3):1051-4

21. Smith LL, Fulmer MG, Holbert D, McCammon MR, Houmard JA, Frazer DD, et al. The impact of a repeated bout of eccentric exercise on muscular strength, muscle soreness and creatine kinase. Br J Sports Med 1994:28:267-271.

22. Malm C, Lenkei R, Sjödin B. Effects of eccentric exercise on the immune system in men. J Appl Physiol 1999;86:461-468

23. Tricoli V. Mecanismos envolvidos na etiologia da dor muscular tardia. Rev Bras Cien Mov 2001;9:39-44.

24. Ascensão A, Rebelo A, Oliveira E, Marques F, Pereira L, Magalhães J. Biochemical impact of a soccer match - analysis of oxidative stress and muscle damage markers throughout recovery. Clin Biochem 2008;41(1011):841-851.

25. Clarkson PM. Antioxidants and physical performance. Crit Rev Food Sci Nutr 1995;35(1-2):131-41.

26. Chevion M, Berenshtein E and Stadtman, ER. Human studies related to protein oxidation: protein carbonyl content as a marker of damage. Free Radical Biol Med 2000;33:S99-S108.
27. Brites FD, Evelson PA, Christiansen MG. et al. Soccer players under regular training showed imcreased oxidative stress but an improved plasma antioxidant status. Clin Sci 1999;96(4):381-385.

28. Tauler P, Ferrer MD, Sureda A, Pujol P, Drobnic F, Tur JA, Pons A. Supplementation with an antioxidant cocktail containing coenzyme Q prevents plasma oxidative damage induced by soccer. Eur J Appl Physiol 2008;104(5):777-85.

29. Nikolaidis MG, Jamurtas AZ, Paschalis V, Fatouros IG, Koutedakis Y, Kouretas D. The Effect of Muscle-Damaging Exercise on Blood and Skeletal Muscle Oxidative Stress: Magnitude and Time-Course Considerations. Sports Med 2008;38(7):579-606.

30. Alessio HM, Hagerman AE, Fulkerson BK, Ambrose J, Rice RE, Wiley RL. Generation of reactive oxygen species after exhaustive aerobic and isometric exercise. Med Sci Sports Exerc 2000;32(9):1576-81.

\section{Endereço para correspondência}

Cláudio Teodoro de Souza

Universidade do Extremo Sul Catarinense UNESC.

Programa de Pós-Graduação em Ciências da Saúde - PPGCS

Laboratorio de Bioquimica e Fisiologia do Esforço Av Universitária 1106, Bairro Universitário 88802-250. Criciúma, SC.

E-mail: ctsouza@unesc.net 